\title{
Achievements and Implications of Care and Support Programme among Orphaned and Vulnerable Children: A Systematic Evaluation of HAF II Project in Kogi State, Nigeria
}

\author{
Ademola L. Adelekan ${ }^{1,8,9}$, Gabriel Musa ${ }^{2}$, Grace Anyebe ${ }^{3}$, Abdullahi \\ Rosemary $^{4}$, Idris Muraina ${ }^{5}$, Emmanuel Ameloko ${ }^{6}$, Emmanuel Alhassan ${ }^{7}$, \\ Williams Shaibu ${ }^{2}$, Patrick Adah ${ }^{2}$, Opeyemi Abiona ${ }^{1,8}$, Fakunle Adekunle ${ }^{1,9}$, \\ Atinuke Agunloye ${ }^{1,10}$, Philomena Omoregie ${ }^{1}$, Segun Adeoye ${ }^{11}$, Michael \\ Olugbile ${ }^{11}$ \\ ${ }^{1}$ Blue Gate Public Health Promotion Initiative, Ibadan, Nigeria \\ ${ }^{2}$ Kogi State Agency for the Control of AIDS, Lokoja, Nigeria \\ ${ }^{3}$ Confluence against AIDS, Lokoja, Nigeria \\ ${ }^{4}$ Total Child Care Initiative, Lokoja, Nigeria \\ ${ }^{5}$ Lift Up Care Foundation, Lokoja, Nigeria \\ ${ }^{6}$ Kogi Women Empowerment Network, Lokoja, Nigeria \\ ${ }^{7}$ Public Private Sector Development Initiative, Lokoja, Nigeria \\ ${ }^{8}$ Department of Health Promotion and Education, Faculty of Public Health, University of Ibadan, Ibadan, \\ Nigeria \\ ${ }^{9}$ THRIVES Project, Department of Medicine, University College Hospital, Ibadan, Nigeria \\ ${ }^{10}$ Department of Radiology, University College Hospital, Ibadan, Nigeria \\ ${ }^{11}$ HIV Programme Development Project (HPDP2), World Bank, Abuja, Nigeria
}

\begin{abstract}
Background: Kogi State recognizes the necessity of meeting the needs of orphans and vulnerable children $(O V C)$ with compassionate care as a result broad range vulnerabilities faced by these children and their families. This paper therefore presents achievements and implications of care and support programme among OVC in Kogi State, Nigeria

Methods: Five civil society organizations were engaged by Kogi State Agency for the Control of AIDS under HIVIAIDS fund (HAF) II project to provide care and support services for OVC. A total of 3700 OVC were reached with this intervention and selection of participants was done using purposive sampling. Data collected using data collection and reporting tools were entered on DHIS2 platform and later exported into and analyzed using Microsoft Excel.

Results: Out of the total of 3700 OVC enrolled in this project, 114 (3.1\%) were lost to follow up, 138 (3.7\%) voluntary withdrawn from the project and 295 (8.0\%) died. The number of household heads provided with economic support was 760. Among these, 60.9\% were supported in 2015. A total of 192 children were also provided with economy strengthening services, 3367 were provided with educational access. In 2015 alone, a total of 1920 representing $51.9 \%$ of the total population were provided with nutritional support, 808 children were provided with protection services while 116 were provided shelter.

Conclusion: Programming for children orphaned and made vulnerable by HIV/AIDS will contribute to the achievement of an AIDS-free generation by responding to the social (including economic) and emotional consequences of the disease on children, their families, and communities that support them. Scale-up of this intervention is therefore recommended.
\end{abstract}

Keyword: Orphans and vulnerable children, HAF II project, HIV, Care and support

\section{Introduction}

The HIV/AIDS epidemic has exacted a terrible toll on children and their families. During the 30 years of the global HIV epidemic, an estimated 17 million children have lost one or both parents due to AIDS; 90 percent of these children live in sub-Saharan Africa. In addition, 3.4 million children under age 15 are living with HIV [1]. Despite some decline in HIV adult prevalence worldwide and increasing access to treatment, the number of children affected by or vulnerable to HIV remains alarmingly high [2]. Worldwide, it is estimated that more than 16 million children under 18 years have been orphaned by AIDS, with 14.8 million of these children in sub-Saharan Africa [3]. Statistics show that the number of orphans due to AIDS alive in 2009 in 
South Africa was 1,900,000. In Uganda, the number was 1,200,000. And in Zimbabwe, the number was 1,000,000. In Nigeria, however, the number was the highest at 2,500,000 [4].

The social and emotional effects of the disease are numerous and profound. While poverty is at the core of many of these issues, HIV/AIDS deeply complicates the environment both for the consequences of and the response to the epidemic. As a result of the social effects of HIV/AIDS, millions of HIV-affected children are highly vulnerable, as they are more likely to be victims of abuse, live in institutional care or on the street, and engage in hazardous and/or exploitive labour. More specifically, children who live with an ill adult or who have been orphaned by AIDS have a dramatically greater risk of abuse and exploitation, [5] school drop-out (as children leave school to care for ailing family members), and psychosocial distress [6-8].Orphaned and vulnerable children are also far more likely to move from being "affected" by the virus to becoming infected, as well as facing other risks [9]. This is especially true for adolescent girls who have lost a mother and who are then more likely to engage in risky sexual behaviour. Kogi State Agency for the Control of AIDS (KOSACA) recognizes the necessity of meeting the needs of these children, orphaned or made vulnerable by HIV/AIDS with compassionate care. Therefore dedicates to the development of evidence-based policies and the implementation of human practices for the care and support of these children. Hence, this article presents achievements and implications of care and support programme among OVC in Kogi State, Nigeria

\subsection{Study Design}

\section{Methodology}

This was an intervention project carried out among OVC including their caregivers in Kogi State, Nigeria. Five civil society organizations (CSOs) namely Public Private Sector Development Initiative (PPSDI), Total Child Care Initiative (TCCI), Lift Up Care Foundation (LUCAF), Kogi Women Empowerment Network (KOWEN) and Confluence Against AIDS (CONFAIDS) were engaged and provided with funding by Kogi State Agency for the Control of AIDS under HIV/AIDS fund (HAF) II project to provide care and support services for orphaned and vulnerable children. This was an eighteen months project carried out between the year 2013 and 2015

\subsection{Study Site}

This project was carried out in Kogi State Nigeria and is located between latitude $6^{\circ} 30^{\prime \prime} \mathrm{N}$ and $8^{\circ} 50^{\prime} \mathrm{N}$ and longitude $5^{\circ} 51^{\prime \prime} \mathrm{E}$ and $8^{\circ} 00^{\prime} \mathrm{E}$. Lokoja, the State capital is generally hot throughout the year, with an average humidity of 68-70\%. Kogi State has a projected population of 3 million people who are mainly farmers. It consists of three major ethnic groups namely: Igala, Ebira and Okun (Yoruba) while the other ethnic groups include Ogoris, Nupe, Kakanda, Hausas, and the Bassas, etc. The State is largely mountainous. Most of the state is rocky and of undulating high lands with an average height of about $1,400 \mathrm{~m}$ above sea level.

\subsection{Target Population}

The target populations for the intervention programme are OVC and their caregivers in seven (Delina, Ofu, Okene, Olamaboro, Ankpa, Kabba-Bunu and Ajaokuta) Local Government Areas. Participants who are paternal orphan, maternal orphan, double orphans and vulnerable ones whose parents are infected with HIV but alive were included in this project.

\subsection{Sample Size}

A total of $3000 \mathrm{OVC}$ were targeted for this intervention and selection of participants was done using purposive sampling. This implies that participants were selected because they are OVC.

\subsection{Description of Intervention}

Advocacy visits were made to health facilities, likewise home visit to provide counseling support based on identified needs of the affected children. Educational materials were also purchased and distributed to the children. Other intervention activities put in place were setting and implementation of referral linkage system with the health facility to access basic medical investigation for all enrolled OVC, sensitization workshop for OVC parents and caregivers on importance of education. Training on capacity strengthening workshop was organised for teachers to improve child educational performance; establishment and strengthening child protection committee was also put in place.

Furthermore, this intervention trained caregivers from vulnerable households on income generating activities and financial management. They were also linked with micro finance and other internal resources. Establishment and supervision of kids' clubs to ensure the functionality of on-going activities; conduct recreation activities e.g. sports, readers club for OVC. Sensitization of households on preventive health measures (immunization, vaccination and nutrition) was also carried out as part of the activities. Facilitate birth 
registration for children without birth certificates, supply of food supplements and training of households on food production and processing for sustainability. Brief details of some of the intervention activities carried out were summarized below;

\subsubsection{Provision of educational materials}

The aim of providing educational materials for OVC is to enable them focus and come out with a very good result to contribute positively to the improvement of their wellbeing in a near future. Vulnerable children were provided with scholastic materials such as mathematical set, pen, pencil, note books, school bags, shoes, eraser etc. Distribution ceremony took place in their various LGAs.

\subsubsection{Home visit to provide counseling support based on identified needs of OVC}

Counselling support was provided to OVC by trained volunteers on a wide-range of issues on HIV status disclosure, ART adherence, personal hygiene, eating healthy and hygienic food, coping with emotions etc. Home visit was conducted by trained volunteers for OVC in all the communities that were selected for this intervention.

\subsubsection{Linking OVC to health facility to access basic medical investigation}

The vulnerable children were referred to health care facility for basic medical investigation (Malaria and HIV testing) and were followed up appropriately.

\subsubsection{Supply of food supplements to OVC from identified household}

As part of the integrated services rendered to children within the reporting period, the CSOs distributed bags of rice, bags of beans, maggi, tomato paste and salts to caregivers aimed at supporting the food security of vulnerable children under their care.

\subsubsection{Quarterly child growth monitoring}

A quarterly child growth monitoring via trained volunteers was carried out during this intervention, the growth monitoring is aimed at determining vulnerable children mid upper arm circumference, a method which gives idea of child's nutrition status.

\subsection{Data Analysis}

Data were collected using various but uniform data collection and reporting tools. The data were collected from various activities carried out under structural intervention, behavioural intervention and biomedical interventions. The data were entered into DHIS2 platform and exported into Microsoft excel. The results were analyzed using Microsoft Excel by comparing frequencies and percentages. They were carefully presented in tables and chart.

\subsection{Ethical Consideration}

Prior to the commencement of the project, the proposal was subjected to a two-stage review and ethical approval to conduct the research was obtained from the National and the State Ethical Review Committee, Federal Ministry of Health, Nigeria after an in-depth review of the proposal for compliance with ethical guidelines. Also, permission was obtained from the leaders of the identified groups where necessary. The criteria for selection of samples included voluntary declaration of participation in the project and the ability for transmission of information.

\section{Results}

The total number of OVC reached during the project period was 3700 given a target reached of $123.3 \%$.

\subsection{Enrollment pattern of clients}

Out of the total of $3700 \mathrm{OVC}$ enrolled in this project $114(3.1 \%)$ were lost to follow up, $138(3.7 \%)$ voluntary withdrawn from the project and $295(8.0 \%)$ died. A total of 1682 children were provided with a minimum of one care, 361 children were provided with prevention with positive services. A total of 38 children were transferred out while only 38 children completed referrals (Table 1).

Table 1: Enrollment pattern of clients

\begin{tabular}{|c|c|c|c|c|c|}
\hline \multirow[t]{3}{*}{ Variables } & \multicolumn{4}{|l|}{ Year } & \multirow{3}{*}{ Total } \\
\hline & \multicolumn{2}{|l|}{2014} & \multicolumn{2}{|l|}{2015} & \\
\hline & n & $\%$ & $\mathbf{n}$ & $\%$ & \\
\hline Children enrolled & 1211 & 32.7 & 2489 & 62.3 & 3700 \\
\hline Children loss to follow-up & 7 & 6.1 & 107 & 93.9 & 114 \\
\hline Children provided with adherence support & 678 & 47.4 & 752 & 52.6 & 1430 \\
\hline
\end{tabular}


Achievements and Implications of Care and Support Programme among Orphaned and Vulnerable ..

\begin{tabular}{|l|l|l|l|l|l|}
\hline Children provided with a minimum of one care & 877 & 52.1 & 805 & 47.9 & 1682 \\
\hline Children provided with prevention with positive service & 48 & 13.3 & 313 & 86.7 & 361 \\
\hline Children voluntarily withdrawn from services & 87 & 63.0 & 51 & 37.0 & 138 \\
\hline Children transferred out & 38 & 62.3 & 23 & 37.7 & 61 \\
\hline Children who completed referrals & 8 & 21.1 & 30 & 78.9 & 38 \\
\hline Children who died & 292 & 99.0 & 3 & 1.0 & 295 \\
\hline
\end{tabular}

\subsection{Care and Support Intervention}

At the onset of the project in the year 2014, the number of household heads provided with economic support was 760. Among these, $60.9 \%$ were supported in 2015. A total of 192 children were also provided with economy strengthening services, 3367 were provided with educational access. In 2015 alone, a total of 1920 representing $51.9 \%$ of the total population were provided with nutritional support, 808 children were provided with protection services while 116 were provided shelter (Table 2).

Table 2: Care and Support Intervention

\begin{tabular}{|l|l|l|l|l|l|}
\hline Care and Support & \multicolumn{2}{l|}{ Year } & \multirow{2}{*}{ Total } \\
\cline { 2 - 5 } & $\mathbf{2 0 1 4}$ & $\mathbf{2 0 1 5}$ & $\mathbf{\%}$ \\
\cline { 2 - 5 } & $\mathbf{n}$ & $\mathbf{\%}$ & $\mathbf{n}$ & $\mathbf{\%}$ & \\
\hline Households heads provided with economic support & 297 & 39.1 & 463 & 60.9 & 760 \\
\hline Children accessing economy strengthening services & 68 & 35.4 & 124 & 64.6 & 192 \\
\hline Children provided with educational access & 1105 & 32.8 & 2262 & 67.2 & 3367 \\
\hline Children accessing healthcare service & 87 & 12.2 & 626 & 87.8 & 713 \\
\hline Children provided with nutritional support & 1079 & 36.0 & 1920 & 64.0 & 2999 \\
\hline Children accessing protection services & 148 & 18.3 & 660 & 81.7 & 808 \\
\hline Children accessing psychosocial services & 554 & 43.1 & 732 & 56.9 & 1286 \\
\hline Children provided with shelter & 98 & 84.5 & 18 & 15.5 & 116 \\
\hline
\end{tabular}

\section{Discussion}

Many of the household heads were provided with economic support in this intervention. This may be attributed to the fact that the capacity of families to protect the rights and ensure the well-being of their children depends largely on the ability of a household to meet immediate needs, ensure a steady income and maintain the integrity of its economic safety net [10]. The HIV pandemic affects the economic stability of families and the children in their care by interrupting income streams, depleting assets, introducing labour constraints, and increasing dependency ratios [11]. Approaches to strengthening the economic and food security of families affected by AIDS need to be a part of the continuum of response to preempt a descent into more extreme vulnerability, improve household welfare, and prevent future risk exposure [12-13]. Conditional cash transfers, insurance mechanisms, direct subsidies and material assistance can help alleviate the urgent needs of the most vulnerable households. Examples of longer-term interventions include introducing members to self-managed savings groups; facilitating access to financial services offered by micro-finance institutions; creating linkages between micro enterprises and more profitable markets or more economical sources for purchasing raw materials; and improving agricultural efficiency [10].

Many children were provided with psychosocial services. Children affected by HIV/AIDS suffer anxiety and fear during the years of parental illness, then grief and trauma with the death of a parent. These problems are often compounded by cultural taboos surrounding discussion of AIDS and death. It cannot be assumed that children and their caregivers are always able to cope without support. They need plenty of opportunity to express their feelings without fear of stigma, discrimination and exclusion. Research has shown that such support is particularly critical for the health and development of children living with HIV/AIDS [14]. Children living with HIV experience more subjective distress than their HIV-negative peers [15-16] and face multiple stressors related to HIV [17]. In addition, several studies suggest that the psychosocial well-being of children and their caregivers can improve adherence to ART and clinical outcomes. There is also evidence that children living in contexts affected by HIV/AIDS may benefit from increased psychosocial attention, due in part to the multiple losses they may suffer, including illness and death of loved ones [18]. Parental death is recognized as one of the most stressful life events a child or adolescent can endure [19]. Interviews conducted in 2005 with orphans and vulnerable children, their parents and caregivers, and students and teachers in communities heavily affected by HIV/AIDS in South Africa and Swaziland found that parental death is one of the major causes of disruption of children's lives [20]. In addition, orphaned children separated from their siblings have significantly higher scores on anxiety, anger, dissociation, and sexual distress than those living with their siblings.

Most of the children were provided with educational access because every child has the right to a primary education. It is vital for children's futures that they attend school and take full advantage of this right. Beyond academic learning, education is also important for their psychosocial development. Schools can provide children with a safe, structured environment, the emotional support and supervision of adults, and the 
opportunity to learn how to interact with other children and develop social networks. Education can also reduce children's risk of HIV infection by increasing knowledge, awareness, skills and opportunities. Established and emerging evidence in the education field demonstrates that sustainable interventions such as school block grants [21-22] and linking communities and schools for integrated support of educational and protection outcomes [23] are positive and sustainable interventions. In addition, researchers have developed a solid foundation of evidence that supports the returns on investment in early childhood development on health outcomes, human capital, and national productivity. This research supports interventions for children under age 5 that promote resilience and mitigate adverse childhood experiences to promote positive brain development and future positive health outcomes [24-25]. Evidence also supports community involvement and the importance of promoting girls education, not only for educational outcomes but also for achieving an AIDS-free generation [10]. Evidence also demonstrates that education can affect infection rates, as "more highly educated girls and young women are more likely to be able to negotiate safer sex and reduce HIV rates" [26].

Almost all the participants were provided with nutritional support. Nutritional intake during a child's first five years is critical to survival and healthy development. In general, differences in nutritional status between boys and girls are negligible from ages 0 to 4 years. As children become adolescents, the risk of nutritional issues, notably anemia, is significantly higher for girls [27]. Few of the children were provided with protection services to provide an outstanding platform for integration, especially since an explicit goal is often to increase access to and utilization of essential services. Within an OVC portfolio, this creates opportunities for leveraging complementary investments in education, health, and nutrition. Social and parasocial workers are frequently the primary frontline agents of social protection efforts, helping to identify eligible families, deliver assistance, and manage casework.

\section{Implications For Programming}

Orphans and vulnerable children community-based programming helps to reduce stigma and discrimination and create an enabling environment for people infected and affected by HIV/AIDS to access services. By addressing socio-emotional effects of the epidemic, OVC programmes reduce the likelihood of children and adolescents moving from being affected by the epidemic to infected. Addressing psychosocial needs does not necessarily require separate programmes. Relevant measures can be incorporated into other activities. Group approaches, peer support and individual counselling are needed. Schools, social welfare programmes, faith-based organizations and other existing structures with the potential to reach AIDS-affected families in their communities can offer much needed support. Teachers, health care workers and others can be trained to identify signs of distress and to take appropriate action. Community-based monitoring and support activities, such as those conducted by women and adolescent volunteers in Zimbabwe, are helping to guide and protect children.9 Some of the elements that have been identified as key to the success of psychosocial support interventions are community ownership, engaging children and young people in planning and implementation, and tailoring activities to local cultural practices and beliefs. In addition, programmes must provide support that is developmentally appropriate, recognizing that children of different ages respond differently to trauma and loss, and need support throughout childhood and youth. Health and nutrition programs within the OVC portfolio should prioritize coordinated evidence-based interventions that aim to improve children's and families' access to health and nutritional services through the use of global best practices. Government, NGOs and social workers focus on the enhancement of the capacity of OVC, especially adolescents, to participate in the process of meeting their own needs. Constructive atmosphere has to be created by government for the parents or relatives to provide welfare for the OVC.

\section{Conclusion}

The intervention reflected that orphaned and vulnerable children sufferings can be ameliorated if they are being provided with basic needs of life (food, house, education and shelter). The programme found out that despite the escalating socio-economic challenges and structural transformation, the family remains the strongest and most prominent unit of care and support of orphaned and vulnerable children. Together with other partners, there should be commitment to providing effective and significant support to the orphans and other vulnerable children. Supporting orphaned and vulnerable children should be a major priority of the society at large. While scaling up is imperative, it is also important that programs reflect sound practices, are evidence-based; remain sensitive to the dynamics of the local epidemic, the cultural context of the state and the national strategy of host Governments; and work to meet the needs of orphaned and vulnerable children in a measurable way. The challenges of a rapidly escalating population of HIV/AIDS-affected children in resource-poor countries require an accelerated and concerted effort of the society and technical teams working on orphaned and vulnerable children. Other identified bodies should work together in designing, implementing and evaluating orphaned and vulnerable children programmes. For the lives of the most vulnerable children in Nigeria to be drastically changed in the coming years, there is need for all sectors to come together in a coordinated response. Key 
stakeholders and implementing partners are to be coordinated by the government at Federal, State and Local Government Area (LGA) levels. Other key players include NGOs, social workers, private sector and media on the support and implementing orphaned and vulnerable children programmes.

\section{Acknowledgement}

The evaluation team wishes to acknowledge the World Bank and the National Agency for the Control of AIDS (NACA) for making available the funding for the evaluation and dissemination of this project intervention.

\section{References}

[1]. The U.S. President's Emergency Plan for AIDS Relief. Guidance for Orphans and Vulnerable Children Programming. July 2012

[2]. Joint United Nations Programme on HIV/AIDS (UNAIDS). (2010). UNAIDS Report on the Global AIDS Epidemic 2010. Geneva: UNAIDS.

[3]. UNAIDS (2012) UNAIDS Report on the Global AIDS Epidemic. http://www.avert.org/aids-orphans.htm [

[4]. UNICEF/UNAIDS (2012) Children and AIDS: Fifth Stocktaking Report. http://www.avert.org/aids-orphans.htm

[5]. Cluver L, Orkin M, Boyes ME, Gardner F, Meinck, F. (2011). Transactional sex amongst AIDS-orphaned and AIDS-affected adolescents predicted by abuse and extreme poverty. Journal of Acquired Immune Deficiency Syndromes. 58, 336-342.

[6]. Guo Y, Sherr L. (2012). The impact of HIV/AIDS on children's educational outcome: A critical review of global literature. AIDS Care. Apr 23 Epub ahead of print.

[7]. Cluver L, Orkin M, Boyes ME, Gardner F. (2012). AIDS-orphanhood and caregiver AIDS-sickness-status: Effects on psychological symptoms in South African youth. Journal of Pediatric Psychology. DOI: 10.1093/jpegsy/jss004. (IF 2.943)

[8]. Atwine B, Cantor-Graae E, Bujunirwe F. (2005). Psychological Distress among AIDS Orphans in Rural Uganda. Science \& Medicine. 61 (3), 555- 564.

[9]. Operario D, Underhill K, Chuong C, Cluver L. (2011). HIV Infection and Sexual Risk Behaviour Among Youth who have Experienced Orphanhood: Systematic Review and Meta-Analysis. International Aids Society. 14:25.

[10]. UNICEF. (2004). Girls, HIV/AIDS and Education.

[11]. African Forum and Network on Debt and Development (AFRODAD). (2007). The Macroeconomic Framework \& the Fight against HIV/AIDS in Africa. No.3. AFRODAD.

[12]. Bachmann M, Booysen, F. (2003). Health and economic impact of HIV/AIDS on South African households: a cohort study. BMC Public Health. 3 (14).

[13]. Fox M et al. (2004). The Impact of HIV/AIDS on Labour Productivity in Kenya. TropMed and International Health. 9 (3), $318-324$.

[14]. King E, De Silva M, Stein A, Patel V. (2009). Interventions for Improving the Psychosocial Well-Being of Children Affected by HIV and AIDS. Cochrane Database of Systematic Reviews (2):CD006733.

[15]. Brown LK, Lourie KJ. (2000). Children and Adolescents Living with HIV and AIDS: A Review. J Child Psychol Psychiat. 41, 8196.

[16]. Cluver L, Gardner F. (2007). The Mental Health of Children Orphaned by AIDS: A Review of International and South African Research. Journal of Child and Adolescent Mental Health. 19 (1), 1-17.

[17]. AIDSTAR-One Project. (2011). Foundation for the Future: Meeting the Psychosocial Needs of Children Living with HIV in Africa. Technical Brief.

[18]. Cluver, L, Gardner, F \& Operario, D (2007). Psychological distress amongst AIDS-orphaned children in urban South Africa Journal of Child Psychiatry \& Psychology \& Allied Disciplines 48(8), 755-763

[19]. Hallman K. (2008). Researching the Determinants of Vulnerability to HIV among Adolescents. IDS Bulletin. 39 (5), 36-44.

[20]. Poulsen, H. (2006). The gendered impact of HIV/AIDS on education in South Africa and Swaziland: Save the Children's experiences. Gender \& Development. 14 (1).

[21]. Africare Innovations in Education. (2006). External Review. 105.

[22]. Center for Global Health and Development. (2011). Evaluating the Effectiveness of School Block Grants for Orphans and Vulnerable Children. Boston: Boston University School of Public Health and School of Education.

[23]. Kirby D, Laris BA, Rolleri L. (2005). Impact of sex and HIV education programs on sexual behaviours of youth in developing and developed countries. Youth Research Working Paper No. 2. Research Triangle Park, N.C.: Family Health International.

[24]. Anda R, Felitti V, Bremner J, et al. (2006.) The enduring effects of abuse and related experiences in childhood: a convergence of evidence from neurobiology and epiemiology. Eur Arch Psychiatry Clin Neurosci. 256,174-186.

[25]. Dong M, Anda R, Felitti VJ, et al. (2004). The interrelatedness of multiple forms of childhood abuse, neglect, and household dysfunction. Child Abuse Negl. 28, 771-784.

[26]. Hargreaves J, Boler T. (2006). Girl power. The impact of girls' education on HIV and sexual behaviour. ActionAid.

[27]. UNICEF. (2011). The State of the World's Children 2011: Adolescence: An Age of Opportunity. New York: UNICEF. 